\title{
Producing Renewable Biodiesel Fuel Using the Transesterification Process
}

\author{
T. W. Chung, Y. J. Chen \\ Department of Chemical Engineering, Chung Yuan Christian University, Taoyuan, Taiwan \\ Email: twchung@cycu.edu/tw, tinachen@cycu.edu.tw
}

Received 22 August 2015; accepted 15 October 2015; published 22 October 2015

\begin{abstract}
Biodiesel fuels are considered an alternative to fossil fuels. This is one of the effective means of transferring solar energy to dynamic energy via photosynthesis. It is also being considered in order to reduce the levels of carbon dioxide production worldwide. Biodiesel fuels are a renewable, biodegradable, and clean energy source. Producing enough biofuels to replace fossil fuels will bring the advantages of reduced air pollution and reduced other environmental impacts of fossil fuels. In this study, the response surface methodology (RSM) was used to design the experimental runs and to discuss the manufacturing variables on the transesterification of palm oil into fatty acid methyl ester (i.e. biodiesel fuel). The variation of the degree of effect for each variable in the transesterification process was observed. A second-order model was obtained to predict the yield of biodiesel fuel and the viscosity as a function of the reaction time, the mass fraction of catalyst in methanol and the molar ratio of methanol to plant oil. The experimental data of the yield and the viscosity of biodiesel fuels in different manufacturing variables are discussed in this study. Analysis of variance (ANOVA) was also applied to discuss the main factor and interaction factor effects of the manufacturing variables on the responses of the yield of unrefined biodiesel fuels. The shortage of farmland in Taiwan is a problem that needs to be solved before mass propagation of biofuels can be accomplished. In southeastern Asia, there are many farms and most energy farm products are cultivated (e.g. palm oil or Jatropha oil). In addition to sunflowers and soybeans in Taiwan, those energy farm products are possible choices for production of biodiesel fuel in Taiwan. The cooperation between Indonesia and Taiwan on the plantation of palm or Jatropha trees in Indonesia has conducted and will be one of the possible ways to solve the problem of the shortage of energy farm products in Taiwan.
\end{abstract}

\section{Keywords}

Renewable, Biodiesel, Palm Oil, Transesterification, Response Surface Methodology (RSM)

\section{Introduction}

Biodiesel fuels are gradually considered as an important renewable energy. As can be found in the open literature, biodiesel fuels can be used in most diesel engines without any modification [1]-[3]. The fallow farmland in Taiwan can also be designated for use in cultivation of energy farm products. The Taiwan government is trying 
to convert the 220,000 hectares of fallow farmlands to cultivation of energy plants as a means of helping the economies of the farm villages and of solving problems in agriculture, environmental impact, and the energy shortage. The selected energy plants are grown in the central and southern parts of Taiwan. A demonstration factory for producing biodiesel fuel was built in 2004. In 2008, the government plans to cultivate 20,000 hectares of energy farm products to produce 9000 tons of biodiesel fuel and to propagate 41,000 tons of biodiesel fuel in Taiwan. After 2010, 2\% biofuel will be added to fossil fuel according to the fuel regulations of Taiwan. This will result in a demand of 80,000 to 100,000 tons of biodiesel fuel per year in Taiwan. By 2015, the demand for biodiesel fuel in Taiwan will rise to 150,000 tons per year [4]. In reality, the shortage of farmland in Taiwan is a problem that needs to be solved. The cooperation between Indonesia and Taiwan on the plantation of palm or Jatropha trees in Indonesia will be one of the possible ways to solve the problem of the shortage of energy farm products in Taiwan. The price of the self-produced biodiesel fuel in Taiwan is still high and cannot compete with fossil diesel fuel. However, to reduce the fossil fuel crisis and environmental impact, the propagation of biodiesel fuels is considered. Since it can replace fossil fuels, solve the air pollution problem, and reduce the production of carbon dioxide, the Environmental Protection Administration, the Bureau of Energy, and the Council of Agriculture are trying to promote the production of biodesel fuels as an important cooperative issue.

The demand for biodiesel fuel is going to be very high all over the world. It is estimated that the need for biodiesel fuel will rise to 105 billion liters in Europe by 2010. However, the total production of the biodiesel fuel at the time will be only 30 billion liters if current trends in production of biodiesel fuel are not changed. Therefore, many new factories for the production of biofuels are being built around the world. It has been noted that Germany is the largest producer and consumer of biodiesel fuel in Europe. In southeastern Asia, Malaysia and Indonesia produce biodiesel fuel from palm oils, and the Philippines produce biodiesel fuel from coconut oils. In Taiwan and Japan, recycled oils or waste edible oils are used to make biodiesel fuel. Since joining the WTO, the Taiwan government has promoted the cultivation of energy plants in fallow farmlands to produce different sources of plant oils for biodiesel fuel.

The objectives of this study are to report the experimental works by using the statistic principles of factorial design and RSM for the analysis of variances, which is rare in the literature, especially for the systemic discussion of manufacturing variables and the interactions between variables in the transesterification process.

\section{Experimental Section}

\subsection{Raw Materials}

The properties and the composition of fatty acids of the palm oil used in this study are measured and listed in Table 1. The methanol (99.8\%), acetic acid (99.8\%), sodium chloride (96\%), and sodium hydroxide (96\%) were bought from the Aldrich Company.

\subsection{Experimental Design}

The manufacturing variables discussed in this study are the molar ratio of methanol to palm oil, the mass fraction of the catalyst $(\mathrm{NaOH})$ in methanol, and the reaction time. In this study, the molar ratios of palm oil to methanol were chosen as 3.6, 6.0, and 8.4. The mass fractions of $\mathrm{NaOH}$ in methanol were $1.0 \mathrm{wt} \%, 1.3 \mathrm{wt} \%$, and

Table 1. The property of the palm oil in this study.

\begin{tabular}{ccc}
\hline Property & Values \\
\hline Acid value (mg KOH/g oil) & $<0.3$ \\
Iodine value (mg Iodine/g oil) & $55-60$ \\
Water content (\%) & $<0.1$ & 38.13 \\
& Palmitic acid (C16:0) & 3.78 \\
Major composition of fatty acids (wt \%) & Stearic acid (C18:0) & 45.83 \\
\hline
\end{tabular}


$1.6 \mathrm{wt} \%$. The reaction times were $40 \mathrm{~min}, 80 \mathrm{~min}$, and $120 \mathrm{~min}$. The kinetic viscosity ( $\mathrm{cSt}$ at $40^{\circ} \mathrm{C}$ ), the yield (wt\%), and the gross heat of combustion (J/g) of the methyl ester were measured with the standard methods.

The desired amount of the catalyst of $\mathrm{NaOH}$ was dissolved into the methanol first. Then $423.6 \mathrm{~g}$ of palm oil was placed into the reactor (a $1000 \mathrm{~mL}$ two-necked flask) to mix with the methanol solution. The reactor was kept at $65^{\circ} \mathrm{C}$ and stirred at a speed of $600 \mathrm{rpm}$. When the color of the palm oil changed from light yellow to brown, the reaction was completed.

The products of the reaction were a mixture of glycerol and methyl ester (i.e. biodiesel fuel). The mixture was placed into a separation funnel and left in the funnel for $15 \mathrm{~min}$ to allow the mixture to separate into two levels. The upper level of the mixture in the funnel was the methyl ester, and the lower level of the mixture was the glycerol, which is usually used to make soap, wax, and cleaner. The methyl ester was distilled at $65^{\circ} \mathrm{C}-70^{\circ} \mathrm{C}$ to recover the methanol. This unrefined methyl ester can be refined further. Acetic acid $(\mathrm{CH} 3 \mathrm{COOH})$ was added to the methyl ester to neutralize the unrefined biodiesel fuel to a $\mathrm{pH}$ value of around 7, and the neutralized solution was washed with saturated salt solution three times to remove the residues of glycerol and $\mathrm{NaOH}$. It should be noted that the washing procedure may cause the soap reaction to change the yield of biodiesel fuel.

\section{Results and Discussion}

Since the effects of manufacturing variables on the response variables discussed by the statistical method have gradually attracted interest in recent years [5], the factorial design and RSM was applied in this study. Compared to the traditional analysis of the "one factor at a time" technique, the factorial design and RSM provides an experimental design to reduce the number of the experimental runs and gives a chance to review the interaction effects between variables. In this study, the factorial design model and RSM was used to identify the three selected manufacturing variables influencing the yield $\left(Y_{1}\right)$ and viscosity $\left(Y_{2}\right)$ of the biodiesel fuel and to understand the interactions between these manufacturing variables [6]. The statistical analysis system for a factorial design of three factors applied in this analysis of the transesterification process was designed, and the coded levels $(+1-1)$ of the manufacturing variables are tabulated in Table 2. A mere 15 experimental runs was enough for this type of analysis. The three manufacturing variables (or factors) chosen in this study were the reaction time $\left(X_{1}\right)$, the mass fraction of $\mathrm{NaOH}$ in methanol $\left(X_{2}\right)$ and the molar ratio of methanol to palm oil $\left(X_{3}\right)$. The responses in the yield and the viscosity of biodiesel fuels are represented as $Y_{1}$ and $Y_{2}$ in Table 3. Since the definition of the yield is the weight ratio of biodiesel product to palm oil, and the biodiesel product still contains some catalyst and residues, which will be washed out in the refining procedure, the value of yield may be higher than $100 \%$. In accordance with the usual assumption, higher order interaction effects are insignificant when compared with lower order interaction effects. A second-order polynomial model with a multiple linear regression to estimate the model coefficients of the terms of main factor $\left(X_{\mathrm{i}}\right)$ and 2-factor interaction $\left(\mathrm{X}_{\mathrm{i}} \mathrm{X}_{\mathrm{j}}\right)$ was calculated using the JMP software algorithm.

$$
\begin{aligned}
Y_{1}= & 101.09+0.87 X_{1}+0.59 X_{2}+3.50 X_{3}-0.95 X_{1} * X_{2}+0.38 X_{1} * X_{3} \\
& +0.83 X_{2} * X_{3}+1.25 X_{1}^{2}+0.66 X_{2}^{2}+0.10 X_{3}^{2} \\
Y_{2}= & 3.65-0.13 X_{1}-0.16 X_{2}-0.99 X_{3}+0.12 X_{1} * X_{2}+0.17 X_{1} * X_{3} \\
& -0.05 X_{2} * X_{3}-0.034 X_{1}^{2}-0.09 X_{2}^{2}+0.94 X_{3}^{2}
\end{aligned}
$$

where $Y_{i}$ is the response variable and $X_{i}$ is the factors. The experimental results agree with the above model well since the coefficient of determination $\left(R_{2}\right)$ was 0.90 and 0.98 for $Y_{1}$ and $Y_{2}$, respectively, for the models of biodiesel fuels.

Table 2. The coded level of the manufacturing variables.

\begin{tabular}{ccccc}
\hline Variable & Symbol & -1 & Coded level \\
\cline { 3 - 5 } & & 40 & 0 & 1 \\
\hline Time (mins) & $X_{1}$ & 1.0 & 80 & 1.6 \\
NaOH (g) & $X_{2}$ & 3.6 & 8.3 \\
\hline
\end{tabular}


Table 3. Representation of factorial design and variables for unrefined biodiesel fuels.

\begin{tabular}{|c|c|c|c|c|c|c|c|c|}
\hline No. & & pattern & & $\mathrm{X} 1$ & $\mathrm{X} 2$ & X3 & Y1 (\%) & $\mathrm{Y} 2(\mathrm{cSt})$ \\
\hline 1 & 0 & - & + & 80 & 1 & 8.4 & 103.6 & 3.59 \\
\hline 2 & - & + & 0 & 40 & 1.6 & 6 & 102.3 & 3.42 \\
\hline 3 & - & 0 & + & 40 & 1.3 & 8.4 & 106.9 & 3.74 \\
\hline 4 & + & 0 & + & 120 & 1.3 & 8.4 & 108.0 & 3.77 \\
\hline 5 & 0 & 0 & 0 & 80 & 1.3 & 6 & 102.8 & 3.28 \\
\hline 6 & 0 & 0 & - & 80 & 1.6 & 3.6 & 100.3 & 5.53 \\
\hline 7 & 0 & 0 & + & 80 & 1.6 & 8.4 & 107.8 & 3.07 \\
\hline 8 & + & - & 0 & 120 & 1 & 6 & 105.6 & 3.41 \\
\hline 9 & - & - & 0 & 40 & 1 & 6 & 100.6 & 3.86 \\
\hline 10 & - & 0 & - & 40 & 1.3 & 3.6 & 99.5 & 5.69 \\
\hline 11 & 0 & - & - & 80 & 1 & 3.6 & 99.4 & 5.85 \\
\hline 12 & + & 0 & - & 120 & 1.3 & 3.6 & 99.1 & 5.05 \\
\hline 13 & + & + & 0 & 120 & 1.6 & 6 & 103.5 & 3.44 \\
\hline 14 & 0 & 0 & 0 & 80 & 1.3 & 6 & 99.6 & 3.85 \\
\hline 15 & 0 & 0 & 0 & 80 & 1.3 & 6 & 100.9 & 3.85 \\
\hline
\end{tabular}

Table 4 shows the statistical analysis including the main factor and interaction factor effects of the manufacturing variables on the responses of the yield of biodiesel fuels. As shown in Table $\mathbf{4}$ the effect of the main factors influencing the response of the yield was significant for the factor of $\mathrm{X}_{3}$ (probability $=0.0024$ ) only. The statements "very significant" (probability $\leq 0.001$ ) or "not significant" (probability $>0.1$ ) are quoted from the statistics book by Montgomery (Box et al., 1978). The definitions of the standard error, the Students' $t$ test, and the probability in Table 4 can be found in statistics books [6] [7] or the author's previous work [8]. Since the probability of the factor was small and its t ratio was comparatively larger, the effect of the factor on the yield of unrefined biodiesel fuel was significant. Table 5 shows the statistical analysis including the main factor and interaction factor effects of the manufacturing variables to the responses of the viscosity of unrefined biodiesel fuels. As shown in Table 5, the effect of the main factors influencing the response of the viscosity was very significant for the factor of $\mathrm{X}_{3}$ (probability $=0.0003$ ) only. Since the probability of the factor was very small and its t ratio was comparatively larger, the effect of the factor on the viscosity of unrefined biodiesel fuel was very significant. It should be noted that the interactions between variables $\left(X_{\mathrm{i}} X_{\mathrm{j}}\right)$ were not significant (probability $>$ 0.1) in Table 4 and Table 5. On the basis of the values of probability, the molar ratio of methanol to palm oil $\left(X_{3}\right)$ is one of the most important variables for manufacturing unrefined biodiesel fuels.

The factor of mass fraction of $\mathrm{NaOH}$ in methanol $\left(X_{2}\right)$ is not significant in the process of biodiesel fuel in the Table 4 and Table 5. As shown in Table 3, the increase of the molar ratio of methanol to palm oil reduces the kinetic viscosity and increases the yield of the biodiesel fuel. As expected, the more methanol used in the transesterification reaction, the more biodiesel fuel obtained. The effects of the mass fraction of $\mathrm{NaOH}$ in methanol and the molar ratio of methanol to palm oil are significant. The deviations of the yield $\left(Y_{1}\right)$ and the viscosity $\left(Y_{2}\right)$ of biodiesel fuels changed for the factors $X_{1}, X_{2}$ and $X_{3}$ in the order of $X_{3}>X_{2}>X_{1}$ are shown in Figure 1. The factor of $X_{1}$ is almost without any deviation in Figure 1. The results demonstrate that the effects of the factors on the yield $\left(Y_{1}\right)$ and the viscosity $\left(Y_{2}\right)$ of biodiesel fuels are significant in the order of $X_{3}>X_{2}>X_{1}$. In addition, the gross heat of combustion of the unrefined biodiesel fuel was in the range of 38,920 to 39,883 J/g. However, its kinetic viscosity, was still in the range of the standard value of 3.5 - 5.0 cSt. 


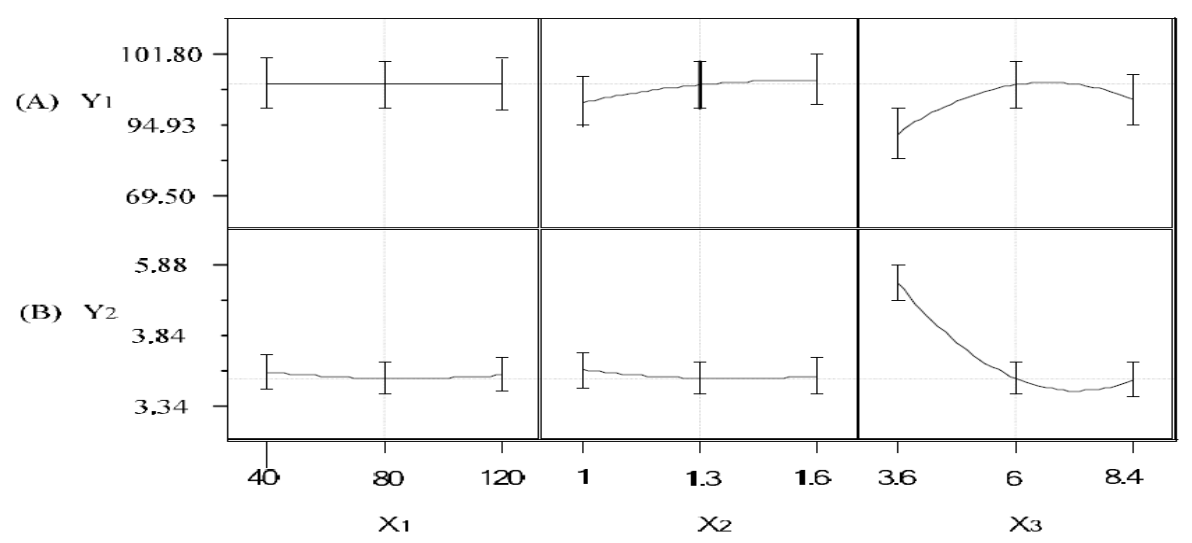

Figure 1. The variation of factors with respect to the responses.

Table 4. Probability for main effects and interaction effects on $Y_{1}$ (yield) for biodiesel fuels. $\left(\mathrm{R}^{2}=0.89\right)$.

\begin{tabular}{ccccc}
\hline Term & Coefficient & Standard Error & Students' test & Probability $>|t|$ \\
\hline Intercept & 101.09 & 1.01 & 99.86 & $<0.0001$ \\
$\mathrm{X}_{1}$ & 0.87 & 0.62 & 1.40 & 0.2212 \\
$\mathrm{X}_{2}$ & 0.59 & 0.62 & 0.95 & 0.3868 \\
$\mathrm{X}_{3}$ & 3.50 & 0.62 & 5.64 & 0.0024 \\
$\mathrm{X}_{1} \mathrm{X}_{2}$ & -0.95 & 0.88 & -1.08 & 0.3280 \\
$\mathrm{X}_{1} \mathrm{X}_{3}$ & 0.38 & 0.88 & 0.44 & 0.6808 \\
$\mathrm{X}_{2} \mathrm{X}_{3}$ & 0.83 & 0.88 & 0.94 & 0.3899 \\
$\mathrm{X}_{1}{ }^{2}$ & 1.25 & 0.91 & 1.37 & 0.2292 \\
$\mathrm{X}_{2}{ }^{2}$ & 0.66 & 0.91 & 0.72 & 0.5037 \\
$\mathrm{X}_{3}{ }^{2}$ & 1.02 & 0.91 & 1.12 & 0.3125 \\
\hline
\end{tabular}

Table 5. Probability for main effects and interaction effects on $Y_{2}$ (viscosity) for biodiesel fuels. $\left(R^{2}=0.96\right)$.

\begin{tabular}{ccccc}
\hline Term & Coefficient & Standard Error & Students' t test & Probability $>|\mathbf{t}|$ \\
\hline Intercept & 3.65 & 0.19 & 19.74 & $<0.0001$ \\
$\mathrm{X}_{1}$ & -0.13 & 0.11 & -1.15 & 0.3033 \\
$\mathrm{X}_{2}$ & -0.16 & 0.11 & -1.38 & 0.2265 \\
$\mathrm{X}_{3}$ & -0.99 & 0.11 & -8.77 & 0.0003 \\
$\mathrm{X}_{1} \mathrm{X}_{2}$ & 0.12 & 0.16 & 0.73 & 0.4965 \\
$\mathrm{X}_{1} \mathrm{X}_{3}$ & 0.17 & 0.16 & 1.04 & 0.3439 \\
$\mathrm{X}_{2} \mathrm{X}_{3}$ & -0.05 & 0.16 & -0.31 & 0.7677 \\
$\mathrm{X}_{1}{ }^{2}$ & -0.03 & 0.17 & -0.20 & 0.8458 \\
$\mathrm{X}_{2}{ }^{2}$ & -0.09 & 0.17 & -0.52 & 0.6256 \\
$\mathrm{X}_{3}{ }^{2}$ & 0.94 & 0.17 & 5.65 & 0.0024 \\
\hline
\end{tabular}

\section{Conclusion}

The biodiesel industry in Taiwan and the analysis of biodiesel fuel production using the transesterifcapion process were discussed and the response surface methodology was used to study the effects of the process variables on the transesterification of palm oil into the biodiesel fuel. As shown in this study, the factor of mass 
fraction of $\mathrm{NaOH}$ in methanol is not significant in the process. However, the effects of the raw materials (methanol and palm oil) on the yield and the viscosity of biodiesel fuels were very significant in the process. Since the reaction time selected in this study was long enough to allow the transesterification reaction, the factor of reaction time had almost no effect on the yield and the viscosity of biodiesel fuels. In addition to the discussions of the yield and the viscosity of biodiesel fuels as related to the trends of process variables, the method of analysis of variances (ANOVA) was used to analyze the effects of the process variables and the interaction between these variables.

\section{References}

[1] Kalam, M.A. and Masjuki, H.H. (2004) Emissions and Deposit Characteristics of a Small Diesel Engine When Operated on Preheated Crude Palm Oil. Biomass Bioenerg, 27, 89-297. http://dx.doi.org/10.1016/j.biombioe.2004.01.009

[2] Almeida, A.C.A., Belchior, C.R., Nascimento, V.G., Vieira, L.S.R. and Fleury, G. (2002) Performance of a Diesel Generator Fuelled with Palm Oil. Fuel, 81, 2097-2102. http://dx.doi.org/10.1016/S0016-2361(02)00155-2

[3] May, C.Y., Liang, Y.C., Foon, C.S., Ngna, M.A., Hook, C.C. and Basiron, Y. (2005) Key Fuel Properties of Palm Oil Alkyl Esters. Fuel, 84, 1717-1720. http://dx.doi.org/10.1016/j.fuel.2005.02.010

[4] Chung, T.W., Chen, Y.J. and Chen, M.T. (2007) Biodiesel Technology and Its Propagation in Taiwan. 3rd International Green Energy Conference (IGEC-III), Vasteras, Sweden, 18-21 June 2007.

[5] Tiwari, A.K., Kumar, A. and Raheman, H. (2007) Biodiesel Production from Jatropha Oil (Jatropha curcas) with High Free Fatty Acids: An Optimized Process. Biomass \& Bioenergy, 31, 569-575. http://dx.doi.org/10.1016/j.biombioe.2007.03.003

[6] Box, G.E.P., Hunter, W.G. and Hunter, J.S. (1978) Statistics for Experimenters. John Wiley and Sons, New York.

[7] Montgomery, D.C. (1997) Design and Analysis of Experiments. John Wiley \& Sons, New York.

[8] Lai, M.H., Chang, Y.N., Wang, C.M., Wu, H.D. and Chung, T.W. (2003) Analysis of the Absorption-Dehumidification Process Variables Using the Experimental Design Methodology. Separation Science and Technology, 38, $2447-2464$. http://dx.doi.org/10.1081/SS-120022282 